$\mathrm{E}$ EVALUAR
2020, Vol. 20, No. 1

ISSN 1667-4545

Recuperado de https://revistas.unc.edu.ar/index.php/revaluar

Laboratorio de Evaluación Psicológica y Educativa Facultad de Psicología - Universidad Nacional de Córdoba

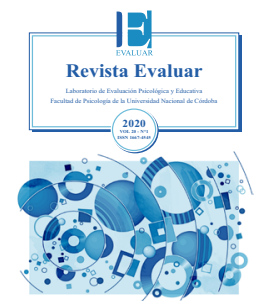

\title{
Validación del Cuestionario de Signos observables asociados a la Inhibición Psicomotriz (SIP)
}

\section{Validation of the Psychomotor Inhibition Signs Questionnaire (SIP)}

\author{
Silvia Saal ${ }^{1 *}$, Josefina Reboursin ${ }^{1}$, María Fernanda Molina ${ }^{1}$ \\ 1 - Universidad Nacional de Tres de Febrero (UNTREF), Caseros, Buenos Aires, Argentina
}

Introducción

Método

Resultados

Discusión

Referencias

Recibido: 06/01/2020 Revisado: 11/03/2020 Aceptado: 03/04/2020

\section{Resumen}

El objetivo de este trabajo es presentar la validación de un instrumento de despistaje: el Cuestionario de Signos observables asociados a la Inhibición Psicomotriz (SIP; Saal, 2019). Participaron 675 niños de entre 5 y 10 años que asistían al primer ciclo de escuelas primarias del Área Metropolitana de Buenos Aires. El análisis factorial exploratorio reveló una estructura bidimensional: inhibición y obediencia. Ambas dimensiones presentan una buena consistencia interna: inhibición, $\alpha=.92$; obediencia, $\alpha=.80$. Si bien ambos factores son conceptualmente relevantes, el puntaje del primer factor se presentó como mejor medida para el rastrillaje de la inhibición psicomotriz en niños de primer ciclo. Tuvo un punto de corte de 35.5 que ofrece la mejor combinación de sensibilidad (.78) y especificidad (.72). El área bajo la curva ROC fue de $.79(p<.001)$. En conclusión, el SIP presenta adecuados indicadores de validez y confiabilidad para su uso como instrumento de despistaje.

Palabras clave: instrumento de despistaje, validación, inhibición psicomotriz, trastorno psicomotor, detección temprana, niñez, escuela primaria

\section{Summary}

The aim of this article is to introduce the validation of a screening tool: the Psychomotor Inhibition Signs Questionnaire (SIP; Saal, 2019). A total of 675 children aged 5 to 10 years attending the three first years of elementary schools of the metropolitan area of Buenos Aires took part in the study. A bidimensional structure: inhibition and obedience, was obtained by exploratory factor analysis. Internal consistency was adequate for both dimensions: inhibition, $\alpha=.92$; obedience, $\alpha=.80$. Even if both factors are conceptually relevant, the first factor's score was found to be a better screening measure for psychomotor inhibition. Cut-off point was established at 35.5 where high levels of sensitivity (.78) and specificity (.72) were obtained. The area under the ROC curve was .79 $(p<.001)$. In sum, these results suggest that this tool is valid and reliable for screening psychomotor inhibition.

Keywords: screening tool, validation, psychomotor inhibition, psychomotor disorder, early detection, childhood, elementary school

*Correspondencia a: Silvia Saal. Calle 12 de Octubre y Las Camelias, Office Quatro, $1^{\text {er }}$ piso, of. 116, Localidad del Viso, Partido de Pilar, Provincia de Buenos Aires. C.P.1669. E-mail: saalsilvia@gmail.com

Cómo citar este artículo: Saal, S., Reboursin, J., \& Molina, M. F. (2020). Validación del Cuestionario de Signos observables asociados a la Inhibición Psicomotriz (SIP). Revista Evaluar, 20(1), 01-16. Recuperado de https://revistas.unc.edu.ar/index.php/revaluar 


\section{Introducción}

El Cuestionario de Signos Observables Asociados a la Inhibición Psicomotriz (SIP; Saal, 2019) es un instrumento de despistaje que fue construido con el objetivo de detectar tempranamente signos de inhibición psicomotriz. La inhibición psicomotriz se encuadra dentro de los trastornos psicomotores que, si bien no guardan correlación con una lesión neurológica u orgánica (De Ajuriaguerra, 1984) implican, en la mayoría de los casos, una perturbación y un padecimiento que entorpece el cuerpo, el movimiento y la comunicación (Bucher, 1978). En la inhibición psicomotriz el movimiento se encuentra disminuido o prácticamente frenado. Esto deja vacante el valor de la experiencia corporal, esencial para el desarrollo en la infancia.

Diversos autores enfatizan que es mediante el cuerpo en movimiento que el niño puede entrar en relación, ponerse en contacto, sentir y expresar una determinada manera de ser y hacer con el cuerpo en el espacio, en el tiempo, con los objetos y con los otros (De León, 2012; Le Boulch, 1992). Se vuelve relevante considerar su papel en el desarrollo de la inteligencia, al ser los movimientos, junto con las percepciones, la base de la inteligencia senso-motora (Piaget \& Inhelder, 1981). El movimiento es el instrumento del que dispone el niño para la acción concreta y la acción es el camino para el acceso al campo de la representación (Wallon, 1965).

Con frecuencia se observa que la merma del movimiento, su disminución o ausencia, no suelen llamar la atención y hasta pueden ser connotadas positivamente. Es habitual que en los distintos ámbitos en los que se desarrolla el niño (en su casa, en la escuela), la reducción del movimiento suela ser asociada por los adultos al portarse bien, al ser buen alumno y, por lo tanto, sea bien recibida, no sea cuestionada ni problematizada
(Saal, 2011).

Por otra parte, cuando el movimiento se presenta en exceso, cuando se evidencia una dificultad para restringirlo y se manifiesta de modo disruptivo ante el entorno, inevitablemente llama y provoca la mirada del otro. El exceso de movimiento ha sido ampliamente estudiado bajo distintas nominaciones, como "hiperactividad, hiperkinesia, hipermovilidad o inestabilidad psicomotriz" (Untoiglich, 2011, p. 50). La hiperactividad, generalmente pensada desde el discurso médico en asociación con la desatención relativa al trastorno por déficit de atención con hiperactividad (American Psychiatric Association, 2014) ha tomado gran protagonismo a partir de fines del siglo pasado, evidenciando en ocasiones un sobrediagnóstico y una creciente medicalización farmacológica (Merten, Cwik, Margraf, \& Schneider, 2017; Rodríguez, 2011; Untoiglich, 2011). La inestabilidad psicomotriz, por su parte, se caracteriza por impulsividad, inquietud y desatención y suele ser el trastorno psicomotor más estudiado y que mayor casuística clínica presenta (Bergés, 1974, 1985; Boscaini, 2013). El amplio estudio de estas temáticas ha dado lugar a desarrollos teóricos y propuestas de intervención tanto en el campo educativo como clínico.

Si afirmamos que el exceso de movimiento debe ser atendido en tanto puede ser la manifestación de un sufrimiento infantil (Untoiglich, 2011), es imperioso interpelarnos acerca de qué les sucede a aquellos niños que se encuentran en el polo opuesto. Consideramos que es de fundamental importancia abordar la posibilidad de que haya un sufrimiento psíquico-corporal concomitante a las conductas que, en general, se tiende a naturalizar.

La reducción del movimiento y del accionar con el cuerpo es uno de los signos característicos de la inhibición psicomotriz. En la inhibición psicomotriz la reducción o retención del movimiento 
y la lentitud en el accionar se presentan sobre un fondo hipertónico. La escasa experiencia corporal trae aparejados signos de torpeza psicomotriz: la posibilidad de ajustarse a los actos cotidianos se desarrolla de manera insuficiente y disarmónica. Se registran también rasgos de timidez, pasividad e hipercontrol (Defontaine, 1980). Cuando esta modalidad de funcionamiento psicomotor se cristaliza y se fija en el tiempo, conlleva malestar y un subyacente padecimiento.

Se considera importante remarcar, de todos modos, que la inhibición como función, es una propiedad operativa del sistema nervioso central que suprime determinadas descargas nerviosas para permitir el flujo de otras (Galimberti, como se citó en Wille, 2007). No se ejerce únicamente para bloquear la actividad, sino que suele presentarse para regular o moderar la impulsividad del gesto (Molina de Costallat, 1987), por lo que cumple un carácter adaptativo en la confrontación con el medio y en el ejercicio de las funciones motrices. Sin embargo, la inhibición se torna patológica cuando se da en exceso, deviniendo expresión de un sufrimiento latente (Benavides, 2003). La inhibición psicomotriz no se define, entonces, por la inhibición de la función exclusivamente, sino que implica la inhibición del funcionamiento y de la realización del cuerpo ligado al movimiento (Bergés, 1974, 1991).

La semiología que caracteriza a la inhibición psicomotriz ha sido descripta por Bucher (1978), quien destaca la voz baja al hablar, la presencia de vacilaciones, la evitación de la mirada del otro, la respiración bloqueada y la escasa expresividad facial. En el marco del diagnóstico, la autora menciona el rechazo por parte de los niños a varias pruebas. De León (2010) refiere que la tensión que frena los movimientos y la pasividad se presentan de modo persistente y atribuye esto a la intención de los niños de pasar desapercibidos. La inhibición psicomotriz ha sido clasifica- da por distintos autores en función de sus maneras de manifestarse. Bergés (1985) distingue la inhibición por hipercontrol y retención, de la inhibición por suspensión de la iniciativa. La primera se caracteriza por un aumento del tono, movimientos frenados y una censura de la actitud y el gesto que se agravan ante la presencia de otras personas. En el segundo caso, el autor ubica la perturbación antes de la acción, en el momento inicial del acto; contrariamente al caso anterior, la presencia de otros tiende a levantar la inhibición. Wille (2007) propone, dentro de la inhibición psicomotriz, una tipología a la que denomina conflictiva, caracterizada por un bloqueo temporal o permanente de la acción, la renuncia al movimiento y un sentimiento de peso de la mirada de los otros, pero conservando el interés hacia el mundo externo. La autora subdivide a esta tipología en dos modos de expresión: acción suspendida y acción tensa. Considera también otra tipología, a la que denomina inercia y la subdivide en las formas autística apática y ajetreada. La autora expresa que esta tipología suele estar asociada al retraso mental grave (Wille, 2012). Saal (2013), a partir de la observación de niños en Argentina, señala que la inhibición psicomotriz puede expresarse en modo vigilante, ligada a la retención del movimiento, cuando el cuerpo no encuentra un modo de evacuar las tensiones, y en modo vacilante, ligada a la reducción del movimiento, temor e indecisión que inhabilitan la acción.

Distintos aspectos del desarrollo del niño están comprometidos en este trastorno psicomotor; Saal (2007) los ha clasificado en siete dimensiones: la expresión verbal gestual, la relación tónico emocional, el movimiento del cuerpo en el espacio, la relación con los pares, la participación y el desenvolvimiento en la escuela, el nivel de autonomía e independencia, y la organización del espacio gráfico. En la Tabla 1 se describen estas dimensiones. 
Tabla 1

Dimensiones de la inhibición psicomotriz.

Dimensión

Expresión verba

gestual

Relación tónico

emocional

Movimiento del

cuerpo en el espacio

Relación con sus pares

Participación $\quad \mathrm{y}$

desenvolvimiento en

la escuela

Nivel de autonomía e independencia

Organización espacio gráfico

\section{Descripción}

Los niños que presentan inhibición psicomotriz suelen hablar con tono de voz bajo, usar monosílabos, se expresan solo cuando se les solicita. La gestualidad y la expresión facial se encuentran empobrecidas.

Se observa aumento de tono muscular, fatiga y bloqueo frente al movimiento, y escasos recursos para regular estados emocionales: con frecuencia se ruborizan cuando hablan y/o cuando los miran o se dirigen a ellos. Esto se incrementa frente al acercamiento y contacto corporal.

Hay retención y repliegue del movimiento; el uso del espacio es mayormente reducido (Bucher, 1978), se refugian cerca de las paredes y rincones (Chokler, 1994). Su actitud es observadora y con poca participación; hay escasa exploración de los objetos y del espacio.

Se muestran evitativos, distantes, poco participativos y solitarios. Suelen seguir a los otros, sin proponer iniciativas propias. En la relación grupal, prefieren pasar desapercibidos. En la relación "uno a uno", esto se atenúa en un vínculo de confianza y seguridad.

Tienden a mostrarse inseguros, temerosos. Se sobreadaptan a las normas y a las exigencias escolares. No se expresan ni se desenvuelven con libertad. No asumen riesgos. Prefieren evitar quedar expuestos a la mirada de los otros.

Se observa una marcada relación de dependencia respecto de la figura del otro. Poca autoría y autonomía de acción. Se muestran lábiles y vulnerables. Suelen dejar lugar a que los otros hagan y hablen por ellos.

del Muestran preferencia por esta forma de expresión. Buen dominio óculo manual. La escritura y el dibujo suelen presentar características micrográficas. Se emplazan en espacios reducidos de la hoja. Tienden a incluir muchos detalles en sus dibujos, o por el contrario, ausencia de detalles y marcada pobreza en el dibujo.
De lo presentado surge que los distintos signos que se asocian a la inhibición psicomotriz tienen en común la particularidad de no convocar a la mirada del otro; se presentan de modo silencioso y suelen quedar ocultos, invisibilizados. No son reconocidos como parte de un funcionamiento que al niño le produce malestar y padecimiento. Esta invisibilidad de la inhibición psicomotriz se ve reforzada por dos vías: por un lado, por ser la inhibición funcional al entorno, al evitar todo tipo de provocación y confrontación, y por otro, por la búsqueda de los niños de pasar desapercibidos ante el peso que tiene para ellos la mirada de los otros. Esto nos plantea, entonces, el desafío de detenernos a observar más allá de lo evidente y de ofrecernos como interlocutores para interpretar el mensaje que expresan la quietud y el silencio del niño inhibido psicomotor como señales de malestar y sufrimiento (Saal, 1995).

Con la intención de dar visibilidad a esta problemática y facilitar la detección temprana de los signos asociados a la inhibición psicomotriz, en el marco de trabajos anteriores (Saal, 2010, 2012, 2014, 2016) elaboramos el instrumento de despistaje SIP. Los instrumentos de despistaje (también denominados de pesquisa o screening) son un modo simple y rápido de identificar posibles retrasos o alteraciones que tienen la particularidad de ser inaparentes (Lejarraga, 2004) y pueden ser aplicados a grandes poblaciones sin necesidad de que quienes los administran sean profesionales (Doménech \& Gómez de Terreros, 1995). Este instrumento no se propone alcanzar un diagnóstico sino constituirse en un primer 
acercamiento, ser una herramienta de orientación que permita identificar indicios, alertar sobre posibles problemas con la intención de prevenir su acentuación.

Al estar diseñado para ser aplicado en las escuelas, el SIP cuenta con dos importantes ventajas: por un lado, es posible aplicarlo a grandes cantidades de niños, y por otro, se cuenta con un actor privilegiado para administrarlo, el docente, que se encuentra a una distancia óptima en relación a ellos (suficientemente cerca para conocerlos en sus modos de ser y hacer, pero no involucrado subjetiva y emocionalmente como los padres). Por estar orientado a la detección temprana, este instrumento se aplica en salas de 4 y 5 años de nivel inicial y en el primer ciclo de la escuela primaria. En este trabajo nos centraremos en los resultados obtenidos en su aplicación en la escuela primaria.

El objetivo de este trabajo es presentar el proceso de validación del SIP para su uso como instrumento de despistaje del trastorno de inhibición psicomotriz en niños de primer a tercer grado (primer ciclo de escolaridad primaria). Se presenta el análisis del funcionamiento de los ítems, el análisis de la estructura interna de la escala y su capacidad de discriminación entre niños con y sin inhibición psicomotriz. Además, se analiza la especificidad y sensibilidad del punto de corte para detectar casos de riesgo.

\section{Método}

\section{Participantes}

Participaron 675 niños $(45.5 \%$ de género masculino y $54.5 \%$ de género femenino) de entre 5 y 10 años $(\mathrm{M}=7.11 ; \mathrm{DE}=0.91)$ que asistían al primer ciclo en cuatro escuelas privadas laicas y religiosas del Área Metropolitana de Buenos Aires (AMBA, Argentina).
El SIP fue completado para cada uno de los niños por su maestra. Se consideró como criterio de exclusión que la maestra fuera suplente y/o hubiera estado al frente del grupo por un tiempo menor a tres meses. También se excluyeron los casos en que los niños participaban de más de un tratamiento ya que los instrumentos de pesquisa se utilizan en niños supuestamente sanos (con este fin se consideraron los tratamientos psicopedagógico, psicológico, fonoaudiológico, psicomotor y neurológico).

Para estudiar la capacidad de discriminación del SIP, del total de la muestra fueron seleccionados 217 niños para arribar a un diagnóstico (ver sección de procedimientos). Para obtener esta submuestra, se tomó a los niños que presentaban mayores puntajes en el SIP y se seleccionaron aleatoriamente niños que no habían obtenido puntajes altos. A partir del diagnóstico, se obtuvo un grupo de 32 niños que presentaban signos de inhibición psicomotriz y un grupo de 185 niños sin signos de inhibición psicomotriz. En la Tabla 2 se presentan las características sociodemográficas de ambos grupos de niños. Como puede observarse, los grupos no presentaban diferencias en las variables sociodemográficas. Si bien se observa una proporción ligeramente mayor de niñas en el grupo que presentaba signos de inhibición psicomotriz, esta diferencia no es estadísticamente significativa $\left(\chi_{(217,1)}^{2}=3.77, p=.052\right)$.

\section{Instrumentos}

El instrumento de despistaje SIP fue elaborado a partir de la profundización teórica sobre el trastorno de inhibición psicomotriz y de información relevada en la casuística clínica. Desde su primera formulación (Saal, 2007), diversos estudios piloto (Saal, 2010, 2012) permitieron ajustarlo progresivamente. Se redujo sensiblemente 
Tabla 2

Características sociodemográficas de los niños con y sin signos de inhibición psicomotriz.

\begin{tabular}{ccc}
\hline & $\begin{array}{c}\text { Niños sin signos } \\
\text { de inhibición } \\
\text { psicomotriz } \\
(\mathbf{n}=\mathbf{1 8 5})\end{array}$ & $\begin{array}{c}\text { Niños con signos } \\
\text { de inhibición } \\
\text { psicomotriz } \\
(\mathbf{n}=\mathbf{3 2})\end{array}$ \\
\hline Edad M (DE) & $7.07(0.94)$ & $7.09(0.93)$ \\
Sexo \% (n) & & \\
Femenino & $47.0(87)$ & $65.6(21)$ \\
Masculino & $53.0(98)$ & $34.4(11)$ \\
Grado & & $37.5(12)$ \\
Primero & $43.8(81)$ & $40.6(13)$ \\
Segundo & $28.1(52)$ & $21.9(7)$ \\
Tercero & $28.1(52)$ & \\
Escolaridad & & $71.9(23)$ \\
Jornada & & $28.1(9)$ \\
simple & $61.6(114)$ & \\
Jornada & & \\
completa & $38.4(71)$ & \\
\hline
\end{tabular}

la cantidad de ítems que lo conformaban y estos fueron reformulados para ser más cercanos al vocabulario docente con el propósito de facilitar su llenado. Los ítems correspondientes a la dimensión espacio gráfico se omitieron debido a que se evidenció que los docentes no solían contar con información suficiente en relación a ella (Saal \& Reboursin, 2017; Saal, Tosto, Moreno, \& Reboursin, en prensa).

El SIP se aplica en la escuela y releva diversos signos asociados a la inhibición psicomotriz. Al ser un instrumento de orientación, no pretende tener un valor diagnóstico acabado sino alertar sobre posibles dificultades. Consiste en un cuestionario que debe ser completado por la docente a cargo del grado o sala para cada uno de sus alumnos. Consta de un primer bloque en el que se relevan datos personales del niño. En una segunda parte, incluye 20 ítems presentados como afirmaciones que se responden mediante una escala Likert de cinco opciones: nunca, poco, a veces, muy frecuente y siempre (Saal \& Reboursin, 2017).

\section{Procedimientos}

El estudio se llevó a cabo durante el período 2013-2017 en escuelas de la Ciudad Autónoma de Buenos Aires y el Gran Buenos Aires; estas fueron seleccionadas deliberadamente en función de contactos previos con las instituciones. En una primera etapa, se realizaron encuentros de sensibilización para poner en común con las docentes las manifestaciones corporales a las que el instrumento hace referencia (tono, postura y gestualidad facial, entre otras). Esto permitió arribar a significados compartidos para ciertos términos presentes en el instrumento y aclarar cualquier duda que pudieran tener. Se les entregó un instructivo con las indicaciones necesarias para completarlo correctamente. Se destacó que el SIP no busca rotular a los alumnos ni proporcionar un juicio valorativo de sus conductas sino proporcionar información sobre la actitud y desenvolvimiento del niño en el ámbito escolar. Se solicitó que fuera completado en ausencia de los alumnos.

Luego de la sensibilización a las docentes, se procedió a la aplicación del instrumento a los 675 niños que conformaron la muestra total. Esta fue realizada a partir del mes de junio (en la mayoría de los casos se llevó a cabo entre los meses de octubre y noviembre). La intención fue garantizar que hubiera finalizado el período de adaptación y favorecer un mayor conocimiento de los niños por parte de las docentes, así como también que los niños estuvieran familiarizados entre ellos, con su maestra, y con el espacio y las pautas de la institución.

Al finalizar la aplicación del instrumento a la muestra completa, se seleccionó una submuestra de 217 niños para establecer el diagnóstico que ofició de regla de oro (Pascucci, 2004) para analizar la capacidad de discriminación de los puntajes obtenidos por el instrumento. El diagnóstico, elaborado por psicomotricistas expertas, se basó en 
observaciones realizadas en la escuela por estudiantes avanzadas y graduadas de la Licenciatura en Psicomotricidad de la Universidad Nacional de Tres de Febrero (UNTREF) que realizaron un entrenamiento de dos años para tal fin. Dichas observaciones tuvieron un carácter no participante, se extendieron por un período de aproximadamente dos meses y fueron programadas anticipadamente para no entorpecer las actividades escolares. Cada grado fue observado por dos observadoras que se mantuvieron constantes con el fin de minimizar la reactividad. Las observaciones fueron orientadas por una guía de pautas.

Para cubrir el despliegue del niño en diversas instancias de su experiencia escolar se abarcaron cuatro situaciones: clase, recreo, clase de Educación Física, y un taller de psicomotricidad programado intencionalmente para observar y registrar el despliegue del movimiento y accionar del cuerpo en relación al espacio, los objetos y los otros (la participación de los niños fue voluntaria, anónima y confidencial, y con consentimiento informado de los padres).

La información registrada a través de las distintas observaciones conformó el material que, junto con producciones gráficas de los niños realizadas en un taller de psicomotricidad y un dibujo libre elaborado en situación de clase con la maestra, fue evaluado y analizado por tres psicomotricistas expertas con amplia experiencia clínica. Las psicomotricistas debieron determinar para cada niño si presentaba signos asociados a la inhibición psicomotriz o no. La evaluación fue llevada a cabo de manera ciega (las evaluadoras desconocían los puntajes obtenidos en el SIP por los niños). Se consideró que un niño presentaba inhibición psicomotriz cuando se cumplían al menos cuatro de los siguientes criterios: a) tensión e incomodidad frente al acercamiento de otro (reacciones de prestancia, aumento del tono muscular); b) escasez y lentitud de movimientos; c) po- co despliegue en el espacio y permanencia en la periferia; d) poca expresividad y mímica gestual; e) tono de voz bajo; f) escasez de interacciones espontáneas con pares y adultos; g) torpeza en el desarrollo de las coordinaciones; h) actitud hiperobservadora con respecto al entorno y repliegue de la acción y el uso del cuerpo; i) escasa disposición al juego corporal. Se consideró necesaria la persistencia de estos signos en al menos dos de las cuatro situaciones observadas: aula, recreo, clase de Educación Física y taller de psicomotricidad.

En los casos en que no hubo acuerdo unánime en las decisiones, se implementó una evaluación colectiva, confrontando los argumentos para arribar a un consenso. Solo se consideró válida una decisión diagnóstica cuando las tres psicomotricistas acordaron. La información que arrojó el SIP fue contrastada con las decisiones diagnósticas.

\section{Análisis de datos}

En primer lugar, se analizó la capacidad de discriminación de los ítems entre niños con y sin inhibición psicomotriz por medio de las curvas de la característica operativa del receptor (ROC, receiver operating characteristic). Se tomó como parámetro el área bajo la curva $(\mathrm{ABC})$. El ABC debe ser mayor a .50 y acercarse a 1 . A su vez, este valor no debe estar incluido en el intervalo de confianza (IC 95\%; Cerda \& Cifuentes, 2012).

Tomando los ítems que presentaban capacidad de discriminar entre los niños con y sin inhibición psicomotriz, se estudió la estructura interna de la escala por medio de un análisis factorial exploratorio (AFE) a través del análisis paralelo (PA; Horn, 1965). Se aplicaron los mínimos cuadrados no ponderados (ULS) para determinar el número de factores a retener (Lorenzo-Seva, 1999). El AFE se basó en matrices de correlacio- 
nes policóricas, ya que son las apropiadas para escalas ordinales (Auné \& Atorresi, 2017; Lloret-Segura, Ferreres-Traver, Hernández-Baeza, \& Tomás-Marco, 2014). Se usó el método de rotación promin (Lorenzo-Seva, 1999). La adecuación de la matriz se evaluó mediante la prueba de Kaiser-Meyer-Olkin (KMO) y la prueba de esfericidad de Bartlett. El criterio de carga elegido para retener cada elemento en cada factor fue que su saturación fuera mayor que .30 (Hair, Anderson, Tatham, \& Black, 2001). Adicionalmente, se calculó el porcentaje de varianza explicada.

Para probar la adecuación del modelo se utilizó, en primer lugar, la raíz media cuadrática residual (RMSR). Se siguió el criterio de Kelley (1935, como se citó en Lloret-Segura et al., 2014) para estimar si este índice arrojaba valores adecuados. Según este criterio, el modelo presenta un ajuste aceptable si el RMSR no excede o si se aproxima a $1 / \sqrt{ } n$ ( $n$ es el tamaño de muestra). Para nuestra muestra este valor debe ser próximo a .04. En segundo lugar, se utilizó la raíz cuadrática media del error de aproximación (RMSEA), que debe presentar valores iguales o inferiores a .08 (Hu \& Bentler, 1999). En tercer lugar, se estimó la raíz cuadrática media ponderada (WRMR). Se considera que valores de WRMR inferiores a 1.0 representan un buen ajuste (Yu \& Muthen, 2002). En cuarto lugar, estimamos el índice de bondad de ajuste (GFI), el índice ajustado de bondad de ajuste (AGFI), el índice de ajuste no normalizado (NNFI) y el índice comparativo de ajuste (CFI). En los últimos cuatro índices se considera que valores superiores a .90 indican un buen ajuste $(\mathrm{Hu}$ \& Bentler, 1999). Para realizar estos análisis se usó el programa Factor (versión 10.9.02, Ferrando \& Lorenzo-Seva, 2017).

Se estudió la confiabilidad por medio del coeficiente alfa de Cronbach y el estimador de fiabilidad ORION (overall reliability of fully-informative prior oblique $N$-EAP scores) propuesto por Ferrando y Lorenzo-Seva (2016). Se considera que son aceptables valores de consistencia interna superiores a .70 (Hair et al., 2001). A su vez, se indagó la homogeneidad por medio de la correlación ítem-total corregida. Se consideró que un puntaje superior a .30 indicaba una adecuada homogeneidad (Tornimbeni, Pérez, \& Olaz, 2008). Para realizar los análisis estadísticos se utilizó el paquete estadístico SPSS (versión 21) para Windows (IBM Corporation, 2012).

Para analizar la capacidad de discriminación de los puntajes del instrumento se calcularon las áreas bajo la curva ROC, la sensibilidad y la especificidad. Se tomó como regla de oro el diagnóstico de inhibición psicomotriz (ver Procedimientos). Estos análisis se utilizaron para determinar el punto de corte óptimo para predecir riesgo de presencia del trastorno.

Para realizar el AFE, el estudio de la confiabilidad y de la homogeneidad, se utilizó la muestra completa. La capacidad de discriminación de los ítems y de los puntajes del instrumento se analizó a partir de la submuestra de 217 casos que habían sido evaluados para establecer el diagnóstico de inhibición psicomotriz.

\section{Resultados}

Estadísticos descriptivos y capacidad de discriminación de los ítems

En la Tabla 3 se presentan los estadísticos descriptivos de los ítems de la primera versión de la escala. Asimismo, en dicha tabla se presentan los resultados de las curvas ROC para cada ítem. Como se puede ver, los ítems 7, 11 y 20 presentan puntajes de $\mathrm{ABC}$ que incluyen en el IC valores inferiores a .50. Esto indica que no discriminan entre los niños con y sin diagnóstico de inhibición psicomotriz. El resto de los ítems presenta puntajes de ABC superiores a .50 (incluyendo el IC). 
Tabla 3

Estadísticos descriptivos de los ítems del SIP

\begin{tabular}{cccccccccccc}
\hline Ítem & Mdn & M & DE & Asimetría & Curtosis & Mínimo & Máximo & ABC & $\begin{array}{c}\text { IC 95\% } \\
\text { ABC }\end{array}$ & $p$ \\
\hline 1 & 3.00 & 2.65 & 1.18 & 0.12 & -0.98 & 1 & 5 & .73 & {$[.64, .82]$} & $<.001$ \\
2 & 2.00 & 2.32 & 1.15 & 0.40 & -0.80 & 1 & 5 & .80 & {$[.72, .88]$} & $<.001$ \\
3 & 1.00 & 1.79 & 0.97 & 1.05 & 0.25 & 1 & 5 & .70 & {$[.60, .81]$} & $<.001$ \\
4 & 2.00 & 2.21 & 1.02 & 0.49 & -0.61 & 1 & 5 & .62 & {$[.51, .73]$} & .033 \\
5 & 2.00 & 2.22 & 1.19 & 0.58 & -0.71 & 1 & 5 & .76 & {$[.69, .84]$} & $<.001$ \\
6 & 2.00 & 2.25 & 1.05 & 0.39 & -0.65 & 1 & 5 & .70 & {$[.61, .79]$} & $<.001$ \\
7 & 2.00 & 2.37 & 1.22 & 0.38 & -0.77 & 1 & 5 & .59 & {$[.47, .71]$} & .107 \\
8 & 2.00 & 2.27 & 1.10 & 0.47 & -0.62 & 1 & 5 & .68 & {$[.59, .77]$} & .001 \\
9 & 4.00 & 3.68 & 1.05 & 0.41 & -0.76 & 1 & 5 & .72 & {$[.63, .80]$} & $<.001$ \\
10 & 3.00 & 2.91 & 1.24 & 0.07 & -1.01 & 1 & 5 & .69 & {$[.59, .79]$} & .001 \\
11 & 1.00 & 1.76 & 1.04 & 1.51 & 0.34 & 1 & 5 & .57 & {$[.46, .68]$} & .198 \\
12 & 2.00 & 2.24 & 1.08 & 0.42 & -0.69 & 1 & 5 & .65 & {$[.54, .75]$} & .008 \\
13 & 3.00 & 3.04 & 1.22 & -0.07 & -0.84 & 1 & 5 & .72 & {$[.62, .81]$} & $<.001$ \\
14 & 2.00 & 1.97 & 1.03 & 0.67 & -0.64 & 1 & 5 & .67 & {$[.58, .76]$} & .002 \\
15 & 4.00 & 3.79 & 0.99 & -0.55 & -0.35 & 1 & 5 & .66 & {$[.55, .77]$} & .004 \\
16 & 3.00 & 3.04 & 0.93 & 0.01 & -0.10 & 1 & 5 & .71 & {$[.61, .80]$} & $<.001$ \\
17 & 1.00 & 1.55 & 0.79 & 1.36 & 1.24 & 1 & 5 & .61 & {$[.50, .73]$} & .042 \\
18 & 3.00 & 3.17 & 1.21 & -0.02 & -1.08 & 1 & 5 & .63 & {$[.51, .76]$} & .015 \\
19 & 2.00 & 1.96 & 1.05 & 0.76 & -0.43 & 1 & 5 & .79 & {$[.70, .87]$} & $<.001$ \\
20 & 1.00 & 1.61 & 0.74 & 1.07 & 0.80 & 1 & 5 & .55 & {$[.44, .67]$} & .341 \\
\hline
\end{tabular}

Nota. $\mathrm{ABC}=$ área bajo la curva. $\mathrm{IC}=$ intervalo de confianza.

Esto implica que poseen una capacidad, mayor que la que se daría por azar, de diferenciar entre niños con y sin diagnóstico de inhibición psicomotriz (Cerda \& Cifuentes, 2012; Hajian-Tilaki, 2013).

\section{Validez factorial}

El coeficiente KMO y la prueba de esfericidad de Bartlett mostraron la suficiencia de la matriz (ver Tabla 4). Se encontró una estructura de dos factores que explican el $72.2 \%$ de la varianza.
El factor inhibición psicomotriz (12 ítems) agrupa los ítems que refieren al núcleo de la inhibición psicomotriz y se vinculan al tono y la emoción, la comunicación y relación con los pares, el movimiento y la participación. El factor obediencia a las normas (3 ítems) guarda relación con el nivel de dependencia del niño en su vínculo con el adulto. Los factores son independientes entre sí $(r=-.04, p=.36)$.

El modelo de dos factores presenta buenos indicadores de ajuste: $\mathrm{RMSEA}=0.07$; $\mathrm{RMSM}=$ 0.04 (valor próximo a 0.04, según el criterio de Kelley, 1935 como se citó en Lloret-Segura et al., 
Tabla 4

Matriz de cargas rotadas SIP.

\begin{tabular}{|c|c|c|}
\hline Ítem & $\begin{array}{l}\text { Inhibición } \\
\text { Psicomotriz }\end{array}$ & $\begin{array}{c}\text { Obediencia } \\
\text { a las normas }\end{array}$ \\
\hline 1. & .84 & \\
\hline 2. & .84 & \\
\hline 3. & .67 & \\
\hline 4. & .60 & \\
\hline 5. & .80 & \\
\hline 6. & .81 & \\
\hline 8. & .85 & \\
\hline 9. & & .83 \\
\hline 10 & .83 & \\
\hline 12. & .74 & \\
\hline 14. & .75 & \\
\hline 15. & & .85 \\
\hline 16. & .59 & \\
\hline 18. & & .71 \\
\hline 19. & .68 & \\
\hline $\begin{array}{l}\% \text { de varianza } \\
\text { explicada }\end{array}$ & 53.40 & 18.82 \\
\hline Eigenvalue & 7.26 & 2.69 \\
\hline
\end{tabular}

Nota. $\mathrm{n}=675 . \mathrm{KMO}=.91$, Prueba de Bartlett: $\chi_{(675,105)}^{2}=$ $5786.5(p<.001)$.

2014); WRMR $=0.05 ; \mathrm{GFI}=0.99 ; \mathrm{AGFI}=.99$; $\mathrm{NNFI}=0.98 ; \mathrm{CFI}=0.99$.

Ambos factores presentan una buena consistencia interna: inhibición, $\alpha=.92$; obediencia, $\alpha=.80$. asimismo, el estimador de confiabilidad ORION indica una buena confiabilidad para ambas subescalas (ver Tabla 5).
Tabla 5

Confiabilidad de las subescalas.

\begin{tabular}{lcc}
\hline & $\begin{array}{c}\text { Inhibición } \\
\text { psicomotriz }\end{array}$ & $\begin{array}{c}\text { Obediencia } \\
\text { a las normas }\end{array}$ \\
\hline Alfa de Cronbach & .92 & .80 \\
ORION & .95 & .88 \\
\hline
\end{tabular}

Los ítems presentan una buena homogeneidad: coeficientes de correlación ítem/total corregida superiores a .30. Ninguno de los ítems aumenta el alfa al ser eliminado (ver Tabla 6).

\section{Tabla 6}

Homogeneidad de los ítems y alpha de Cronbach si se elimina un elemento.

\begin{tabular}{ccc}
\hline Ítem & $\begin{array}{c}\text { Correlación ítem/total } \\
\text { corregida }\end{array}$ & $\begin{array}{c}\text { Alpha si se elimina } \\
\text { el ítem }\end{array}$ \\
\hline 1. & \multicolumn{2}{c}{ Inhibición psicomotriz } \\
2. & .76 & .91 \\
3. & .77 & .91 \\
4. & .57 & .92 \\
5. & .54 & .92 \\
6. & .73 & .91 \\
8. & .73 & .91 \\
10. & .77 & .91 \\
12. & .75 & .91 \\
14. & .64 & .92 \\
16. & .66 & .92 \\
19. & .54 & .92 \\
& .60 & .92 \\
18. & .60 & .69 \\
\hline. & .65 & .76 \\
\hline
\end{tabular}


Tabla 7

Puntos de corte, sensibilidad, especificidad y área bajo la curva de las dimensiones de la inhibición psicomotriz.

\begin{tabular}{lcccccc}
\hline \multicolumn{1}{c}{ Dimensión } & Punto de corte & Sensibilidad & Especificidad & ABC & IC 95\% ABC & $\boldsymbol{p}$ \\
\hline $\begin{array}{l}\text { Inhibición } \\
\text { Psicomotriz }\end{array}$ & 35.5 & .78 & .72 & .79 & {$[.72, .87]$} & .001 \\
$\begin{array}{l}\text { Obediencia a las } \\
\text { normas }\end{array}$ & 9.5 & .82 & .48 & .70 & {$[.59, .80]$} & .001 \\
\hline
\end{tabular}

Sensibilidad, especificación y capacidad de discriminación

El ABC del primer factor fue de $.79(p<$ .001 ; ver Tabla 7). Se estableció un punto de corte de 35.5, que ofrece la mejor combinación de sensibilidad (.78) y especificidad (.72). El ABC para el segundo factor fue de $.70(p<.001)$. Sin embargo, el punto de corte (9.5) ofrece una buena sensibilidad (.82), pero una baja especificidad (.48).

\section{Discusión}

El presente trabajo tuvo como objetivo presentar el proceso de validación del SIP para su uso como instrumento de despistaje del trastorno de inhibición psicomotriz en niños de primer a tercer grado (primer ciclo de escolaridad primaria). El desarrollo y la validación de este instrumento obedecen a la necesidad de contar con un instrumento útil para detectar tempranamente el trastorno de inhibición psicomotriz.

Al tratarse de niños que no generan disturbios en su relación con el entorno, obedientes, muchas veces sobreadaptados a los requerimientos que se les imponen; con escasa y limitada participación; con poco uso del cuerpo como modo de expresar, a través del movimiento y de la acción, una modalidad de conquista activa y prota- gónica; los niños con inhibición psicomotriz suelen pasar desapercibidos e inadvertidos por el entorno. Así, es bastante extraño que se identifique esta sintomatología como una posible alteración que impacta en su estructuración psíquica-corporal. Por estos motivos se ha considerado necesario plantear estos signos como un problema que trasciende la investigación científica y académica, ya que su lectura por las personas en el entorno y los modos en que se manifiesta, suelen ser en líneas generales valorados como señales positivas de conducta obediente (muchas veces por desconocimiento, otras por resultar poco disruptivos al entorno). Al tratarse de un aspecto de la conducta de los niños que no está problematizado en el contexto social y escolar, la "buena conducta" asociada a la inhibición psicomotriz hace que se dificulte visibilizar y reconocer el malestar y padecimiento que a ella se asocian, como un funcionamiento perturbador para el niño, su niñez y su infancia (Saal, 2011, 2013; Saal \& Reboursin, 2017).

A partir de los resultados presentados se puede inferir que el SIP es un instrumento confiable y válido para identificar y visibilizar niños en riesgo de presentar inhibición psicomotriz. La evidencia encontrada señala que los ítems que componen la escala presentan una adecuada capacidad de discriminación y una buena homogeneidad.

En cuanto a la validez factorial, se ha logrado identificar una estructura interna de dos dimen- 
siones empíricas con sentido teórico. La primera dimensión, inhibición psicomotriz (12 ítems) abarca los ítems que se desprenden de cinco de las siete dimensiones teóricas consideradas: relación tónico-emocional, expresión verbal-gestual, movimiento del cuerpo en el espacio, participación y desenvolvimiento en la escuela y relación con los pares. Se constituye así en una dimensión empírica que cubre el núcleo de la inhibición psicomotriz, considerando sus signos centrales.

Resulta relevante destacar que los ítems que hacen referencia al movimiento no se han incluido en la versión final del instrumento, habida cuenta de que las primeras formulaciones del instrumento (en las que se consideraban explícitamente los desplazamientos en el espacio) mostraron una tendencia de las docentes a marcar para todos los niños la ausencia de movimiento, que podría estar en relación con lo que se considera esperable y deseable en el marco de la institución escolar.

Los ítems que estudian el desenvolvimiento del niño en los recreos no se incluyen en ninguno de los factores, debido a que los resultados mostraron que estos ítems no permiten discriminar entre los niños que presentan inhibición psicomotriz y los que no. Consideramos que esto podría deberse a distintos motivos. Por un lado, podría pensarse que las docentes utilizan el momento del recreo como un momento de descanso, en el que su atención está focalizada en el cuidado de los niños (evitando que se lastimen, o que se peleen) pero no lo valoran como un espacio para observar y conocer mejor a los niños. Otra posibilidad es que se deslice en las respuestas de las docentes lo que consideran como esperable para la instancia del recreo, esto es, que los niños participen y disfruten de él.

La segunda dimensión, obediencia a las normas (3 ítems) se relaciona con la dimensión teórica de nivel de autonomía e independencia en relación al otro, en particular a la figura del do- cente. Las dimensiones empíricas mencionadas no presentan una asociación significativa entre sí. Esto quiere decir que, aunque ambas son aspectos relacionados con este trastorno, se presentan de manera independiente. Por este motivo, no se considera indicado calcular un puntaje total para la escala.

En cuanto a la confiabilidad de la escala, se encontraron buenos índices de consistencia interna y del estimador de confiabilidad ORION. Asimismo, la consistencia interna no aumenta al eliminar ninguno de los ítems.

Por otro lado, el análisis de las curvas ROC presenta evidencia estadísticamente significativa de que los puntajes obtenidos por el instrumento permiten diferenciar entre niños con y sin inhibición psicomotriz. Asimismo, se pudo identificar un puntaje de corte para la primera dimensión con adecuados niveles de sensibilidad y especificidad. Esto indica que dicha dimensión es una buena medida para el rastrillaje de la inhibición psicomotriz en niños de primer ciclo. Sin embargo, no se pudo identificar un punto de corte para la segunda dimensión que combine adecuados niveles de sensibilidad y especificidad. De todos modos, sería relevante que futuras investigaciones analicen las posibilidades de combinar estas subescalas para potenciar la capacidad del instrumento de identificar casos de riesgo de inhibición psicomotriz.

Cuando los puntajes altos en la dimensión de obediencia se presentan junto con valores altos en la dimensión de inhibición psicomotriz, la primera de ellas indicaría un alto nivel de dependencia del otro, de sumisión. Por otra parte, cuando los puntajes en la dimensión de obediencia no se acompañan de altos valores en la dimensión de inhibición psicomotriz, sino que se asocian a altos niveles de participación en la escuela (niños que participan activamente, que se ofrecen para mostrar sus trabajos y presentar sus ideas), suelen ser 
indicios de los tipos de conducta que tradicionalmente se asocian con los "buenos alumnos" que respetan las normas.

De este modo, el SIP se presenta como un instrumento válido y confiable que permite discriminar estas dos situaciones. Por un lado, conductas propias de lo que supone ser un buen alumno, obediente y ordenado, sin que ello implique un padecimiento, sino solo un modo de ser y estar. Por otro lado, una situación bien distinta, estaría vinculada a una alteración en la utilización y en el despliegue del funcionamiento y accionar del cuerpo, que coarta y bloquea el desarrollo creativo, autónomo y enriquecido.

Al ser los signos asociados a la inhibición psicomotriz poco molestos, silenciosos, poco disruptivos para la institución educativa y para el entorno, el problema a plantear está emparentado a su escasa visibilización; lo cual podría explicar que no haya antecedentes sobre instrumentos que permitan evaluar esta problemática en la que se ven afectados los niños en el devenir de su infancia como sujetos plenos de derechos para expresarse con plenitud. Esta situación de invisibilidad de la inhibición psicomotriz es opuesta a la de notable visibilización que alcanzan afecciones como la inestabilidad psicomotriz (Bergés, 1974) o el trastorno por déficit de atención con hiperactividad (American Psychiatric Association, 2014) que ya hemos esbozado en un apartado anterior.

El contraste en cuanto a la profundización conceptual y al desarrollo de investigaciones en relación a estos dos trastornos radica en que los niños que presentan inestabilidad psicomotriz provocan y llaman a la mirada del otro (Bergés, 1985), generando malestar en el entorno, mientras que los niños más retraídos, inhibidos, suelen pasar desapercibidos.

Por otra parte, el presente trabajo no está exento de limitaciones. En primer lugar, se trabajó con una muestra no probabilística y por conve- niencia. Por esta razón los resultados no son directamente generalizables a todos los niños de primer ciclo de Argentina. Sin embargo, se contó con una muestra heterogénea de niños pertenecientes a escuelas laicas y religiosas, y de zonas del AMBA con distinto nivel socioeconómico. De todos modos, sería importante que futuras investigaciones repliquen este estudio con niños de otras regiones del país y de áreas rurales. En segundo lugar, ante la imposibilidad de observar a todos los niños para los que se administró el SIP, se debió tomar una submuestra para realizar las decisiones diagnósticas. Al ser los niños con puntajes altos en el SIP una minoría (lo que guardaría relación con la baja incidencia de la inhibición psicomotriz en la población), tomar esta submuestra aleatoriamente podría haber traído aparejado el inconveniente de que los casos de puntajes altos en el SIP no formaran parte de ella. Se tomó, por ello, a los niños que presentaban puntajes altos en el instrumento y se completó aleatoriamente el resto de cada grado para garantizar que la variedad de puntajes en el SIP estuvieran representados en la submuestra. Futuros estudios deberán replicar este análisis tomando una muestra aleatoria, lo suficientemente grande como para incluir la cantidad necesaria de niños con altos puntajes en el SIP.

Habiendo ya aclarado que el SIP no es una herramienta diagnóstica, sino que, en tanto despistaje, es un primer acercamiento que alerta acerca de la presencia de signos asociados a la inhibición psicomotriz, podemos afirmar que este instrumento brinda la información necesaria para actuar oportunamente con la intención de prevenir su acentuación. Esto se puede implementar, según el caso, ofreciendo herramientas a los docentes o haciendo posible la solicitud de una interconsulta y/o derivación a un especialista para que los niños reciban un diagnóstico y tratamiento adecuado. Arribar a un diagnóstico implica una tarea del profesional psicomotricista implementando técni- 
cas y métodos específicos del quehacer psicomotor que exceden el propósito de este instrumento.

Sobre la base de estos análisis, los resultados obtenidos demuestran la importancia de validar este instrumento ya que quienes lo aplican, los docentes, cuentan con la oportunidad de observar a los niños en diferentes instancias del tránsito escolar, lo que brinda a su vez al psicomotricista la posibilidad de conocer estas facetas, y aportar una interpretación más completa de lo observado. La cantidad de casos relevados que presentaban signos asociados a la inhibición psicomotriz confirman lo beneficioso y adecuado de su implementación en el primer ciclo. Se evidencia así el lugar protagónico que adquiere el cuerpo, el accionar concreto en la realidad y el despliegue activo e interactivo en esta etapa vital del desarrollo del niño en el proceso de su infancia. Todos estos son procesos fundantes para la construcción y apropiación de los aprendizajes.

Al mismo tiempo es fundamental destacar la importancia de contar con esta herramienta de aplicación que complementa al campo de la educación con la promoción en el campo de la salud. Se abre un espacio innovador con nuevas oportunidades de acercamiento, de intercambio e interacción temprana, oportuna y directa entre profesionales psicomotricistas y docentes a la hora de evaluar diferentes modos de intervención.

Consideramos que problematizar esta modalidad corporal es el camino para intervenir oportuna y eficazmente. Rescatamos que al implementarse el instrumento de despistaje SIP, este, junto con la sensibilización que lo antecede, tendrá consecuencias también en la mirada de las maestras, que como pudimos registrar a lo largo de la investigación, se solidarizan con la mirada psicomotriz hacia el funcionamiento integral y autónomo del cuerpo del niño en sus modos de ser y estar.

\section{Referencias}

De Ajuriaguerra, J. (1984). Manual de psiquiatría infantil (4 ${ }^{\mathrm{a}}$ ed.). Barcelona, España: Masson.

American Psychiatric Association. (2014). Manual diagnóstico y estadístico de trastornos mentales ( $\left.5^{\mathrm{a}} \mathrm{ed}\right)$. Madrid, España: Médica Panamericana.

Auné, S. E., \& Attorresi, H. F. (2017). Dimensionalidad de un Test de Conducta Prosocial. Revista Evaluar, 17(1), 29-37. doi: 10.35670/1667-4545.v17. n1.17072

Benavides, T. (2003). La clinique psychomotrice. En T. Benavides, Sémiologie psychomotrice de l'enfant (pp. 11-22). París, Francia: Université Paris - VI. Faculté de Médecine Pierre et Marie Curie.

Bergés, J. (1974). Algunos temas de investigación en psicomotricidad. Cuadernos de Terapia Psicomotriz, 1, $5-14$.

Bergés, J. (1985). Los trastornos psicomotrices en la infancia. En S. Lebovici, R. Diatkine \& M. Soulé (Coords.), Traité de psychiatrie de l'enfant et de l'adolescent. París, Francia: Universitaries de France.

Bergés, J. (1991). El cuerpo: De la neurofisiología al psicoanálisis. Cuadernos de Psicomotricidad y Educación Especial, 1(2), 5-15.

Boscaini, F. (2013). Por una contribución al debate sobre la inestabilidad psicomotora. En F. Boscaini (Comp.), Clínica Psicomotriz (pp. 183-194). Verona, Italia: CISERPP.

Bucher, H. (1978). El esquema de una investigación. En H. Bucher, Estudio de la personalidad del niño a través de la exploración psicomotriz (pp. 39-48). Barcelona, España: Toray Masson.

Cerda, J., \& Cifuentes, L. (2012). Uso de curvas ROC en investigación clínica. Aspectos teórico-prácticos. $R e$ vista Chilena de Infectología, 29(2), 138-141. doi: 10.4067/s0716-10182012000200003

Chokler, M. (1994). Los organizadores del desarrollo psicomotor. Buenos Aires, Argentina: Cinco.

De León, C. (2010). Una propuesta de clasificación. En C. De León, Las alteraciones psicomotrices. Diagnós- 
tico en psicomotricidad (pp. 57-90). Montevideo, Uruguay: Tradinco.

De León, C. (Coord.). (2012). Diálogos con Bernard Aucouturier. Montevideo, Uruguay: Espacio Lunes.

Defontaine, J. (1980). Manual de reeducación psicomotriz. Barcelona, España: Médica y Técnica.

Domènech, E., \& Gómez de Terreros, M. (1995). Evaluación psicológica en la temprana infancia. En F. Silva Moreno (Ed.), Evaluación psicológica en niños y adolescentes (pp. 173-219). Madrid, España: Síntesis.

Ferrando, P. J., \& Lorenzo-Seva, U. (2016). A note on improving EAP trait estimation in oblique factor-analytic and item response theory models. Psicológica, 37(2), 235-247. Recuperado de https://www. uv.es/psicologica

Ferrando, P. J., \& Lorenzo-Seva, U. (2017). Program FACTOR at 10: Origins, development and future directions. Psicothema, 29(2), 236-240. Recuperado de http://www.psicothema.com

IBM Corporation. (2012). IBM SPSS Statistics 21.0. [software de cómputo]. Armonk, NY: IBM.

Hajian-Tilaki, K. (2013). Receiver Operating Characteristic (ROC) curve analysis for medical diagnostic test evaluation. Caspian Journal of Internal Medicine, 4(2), 627-635. Recuperado de http://caspjim.com

Hair, J., Anderson, R., Tatham, R., \& Black, W. (2001). Análisis multivariante (5 ${ }^{\mathrm{a}}$ ed.). Madrid, España: Prentice Hall Iberia.

Horn, J. (1965). A rationale and test for the number of factors in factor analysis. Psychometrika, 30(2), 179185. doi: $10.1007 / \mathrm{bf02289447}$

Hu, L., \& Bentler, P. M. (1999). Cut-off criteria for fit indexes in covariance structure analysis: Conventional criteria versus new alternatives. Structural Equation Modeling, 6(1), 1-55. doi: 10.1080/10705519909540118

Le Boulch, J. (1992). Hacia una ciencia del movimiento humano. Introducción a la psicokinética. Barcelona, España: Paidós.

Lejarraga, H. (2004). La pesquisa de problemas de desarrollo. La Prueba Nacional de Pesquisa. En H. Lejarraga
(Ed.), Desarrollo del niño en contexto (pp. 463-475). Buenos Aires, Argentina: Paidós.

Lloret-Segura, S., Ferreres-Traver, A., Hernández-Baeza, A., \& Tomás-Marco, I. (2014). El análisis factorial exploratorio de los ítems: Una guía práctica, revisada y actualizada. Anales de Psicología, 30(3), 11511169. doi: 10.6018/analesps.30.3.199361

Lorenzo-Seva, U. (1999). Promin: A method for oblique factor rotation. Multivariate Behavioral Research, 34(3), 347-365. doi: 10.1207/s15327906mbr3403_3

Merten, E. C., Cwik, J. C., Margraf, J., \& Schneider, S. (2017). Overdiagnosis of mental disorders in children and adolescents (in developed countries). Child and Adolescents Psychiatry and Mental Health, 11(1), 1-11. doi: 10.1186/s13034-016-0140-5

Molina de Costallat, D. (1987). Psicomotricidad III. Educación gestual. Buenos Aires, Argentina: Losada.

Pascucci, M. C. (2004). Validación de instrumentos de pesquisa de trastornos de desarrollo. En H. Lejarraga (Ed.), Desarrollo del niño en contexto (pp. 477-515). Buenos Aires, Argentina: Paidós.

Piaget, J., \& Inhelder, B. (1981). Psicología del niño (10 ed.). Madrid, España: Morata.

Rodríguez, M. B. (2011). Déficit atencional. Perspectiva psicomotriz en la comprensión de una temática actual. En L. González (Comp.), Temas de investigación en psicomotricidad (pp. 35-56). Sáenz Peña, Argentina: Eduntref.

Saal, S. (1995). Psicomotricidad y el niño inhibido. Crónicas clínicas en relajación terapéutica y psicomotricidad, 3, 38-49.

Saal, S. (2007). Caracterización y estudio del trastorno de inhibición psicomotriz (Tesis de licenciatura inédita). Universidad Nacional de Tres de Febrero, Tres de Febrero, Buenos Aires, Argentina.

Saal, S. (2010). Desarrollo de un instrumento de despistaje del Trastorno de inhibición Psicomotriz en la infancia (TIP) a través del reconocimiento de sus signos asociados. Proyecto de Investigación correspondiente a la programación científica 2010-2011. Universidad Nacional de Tres de Febrero, Caseros, Buenos 
Aires, Argentina.

Saal, S. (2011). Caracterización y estudio del trastorno de inhibición psicomotriz. En L. González (Comp.), Temas de investigación en psicomotricidad (pp. 7-34). Sáenz Peña, Argentina: Eduntref.

Saal, S. (2012). Ajustes a un instrumento de despistaje del Trastorno de Inhibición Psicomotriz en la infancia (TIP) y primeras aproximaciones a su validación. Proyecto de Investigación correspondiente a la programación científica 2012-2013. Universidad Nacional de Tres de Febrero, Caseros, Buenos Aires, Argentina.

Saal, S. (2013). Sui "buoni comportamenti" e i "bravi scolari”. Uno sguardo sull'inibizione psicomotoria ne11 'ambito scolastico. Res. Richerche e studi in psicomotricitá, XXI(2), 5-10.

Saal, S. (2014). Avances y mejoras al instrumento de despistaje del trastorno de inhibición psicomotriz en la infancia TIP e información relevada de los primeros cruces con el criterio externo (observación e interpretación diagnóstica). Proyecto de Investigación correspondiente a la programación científica 20142015. Universidad Nacional de Tres de Febrero, Caseros, Buenos Aires, Argentina.

Saal, S. (2016). Validación del instrumento de despistaje del trastorno de inhibición psicomotriz en la infancia TIP. Proyecto de Investigación correspondiente a la programación científica 2016-2017. Universidad Nacional de Tres de Febrero, Caseros, Buenos Aires, Argentina.

Saal, S., \& Reboursin, J. (2017). ¿Cuándo el planteo del problema se vuelve un problema a plantear? Hacia la validación de un instrumento de despistaje de la inhibición psicomotriz. En N. Fernández-Lamarra (Org.), Políticas, actores y prácticas. Estudios de política y administración de la educación III (pp. 385-402). Sáenz Peña, Argentina: Eduntref.

Saal, S. (2019). Cuestionario de Signos Observables Asociados a la Inhibición Psicomotriz (SIP). Dirección Nacional del Derecho de Autor. Propiedad intelectual número: RE-2019-06247311-APN-DNDA\#MJ. Re- ferencia: RL-2019-06247248-APN-DNDA\#MJ.

Saal, S., Tosto, P., Moreno, J., \& Reboursin, J. (en prensa). ¿Cómo visibilizar los signos asociados a la inhibición psicomotriz? Cartografía de una investigación. En L. González (Comp.), La construcción de un oficio. Investigaciones en Psicomotricidad 2009-2018. Buenos Aires, Argentina: Eduntref.

Tornimbeni, S., Pérez, E., \& Olaz, F. (2008). Introducción a la Psicometría. Buenos Aires, Argentina: Paidós.

Untoiglich, G. (2011). Versiones actuales del sufrimiento infantil. Una investigación psicoanalítica acerca de la desatención y la hiperactividad. Buenos Aires, Argentina: Noveduc.

Wallon, H. (1965). Los orígenes del carácter en el niño. Buenos Aires, Argentina: Lautaro.

Wille, A. M. (2007). L'inibizione psicomotoria. L'azione tesa e l'azione sospesa. Napoli, Italia: Cuzzolin.

Wille, A. M. (2012). L'inerzia decisionale. La terapia psicomotoria con persone senza iniziativa motoria e con grave ritardo mentale. Napoli, Italia: Cuzzolin.

Yu, C., \& Muthen, B. (2002). Evaluation of model fit indices for latent variable models with categorical and continuous outcomes. Trabajo presentado en el Annual Meeting of the American Educational Research Association, New Orleans, LA. 